\title{
A Critical Reappraisal of Off-Label Use of Photodynamic Therapy for the Treatment of Non-Neoplastic Skin Conditions
}

\author{
Giuseppe Monfrecola ${ }^{a}$ Matteo Megna ${ }^{a}$ Chiara Rovati ${ }^{b}$ Mariachiara Arisi ${ }^{b}$

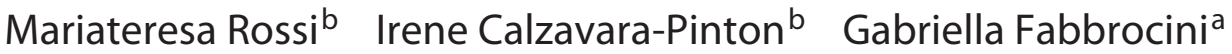 \\ Piergiacomo Calzavara-Pinton ${ }^{\text {b }}$ \\ a Section of Dermatology, Department of Clinical Medicine and Surgery, University of Naples Federico II, Naples, \\ Italy; ${ }^{b}$ Dermatology Department, University of Brescia, Brescia, Italy
}

\section{Keywords}

Photodynamic therapy (PDT) · Off-label PDT .

Non-neoplastic conditions

\begin{abstract}
Background: In the past 30 years, topical photodynamic therapy (PDT) has been investigated for the treatment of a broad spectrum of cosmetic, inflammatory, and infectious skin conditions with variable, and often contrasting, results. However, the non-expert clinician may be in difficulty evaluating these results because different sensitizers, concentrations, formulations, light sources, and irradiation protocols have been used. In addition, many of these studies have poor quality design being case reports and uncontrolled studies of few cases. Summary: With the aim to clarify the potential usefulness of PDT for the treatment of infectious and inflammatory skin diseases as well as selected cosmetic indications, we searched for randomized controlled clinical trials, non-randomized comparative studies, retrospective studies, and case series studies with a number of at least 10 patients, published since 1990. Later, we reappraised the results in order to give a simple critical overview. Key Messages:
\end{abstract}

Evidence from the literature seems to strongly support the use of ALA- and MAL-PDT for the treatment of common skin diseases such as acne, warts, condylomata, and Leishmania skin infection and for photorejuvenation, i.e., the correction of selected cosmetic changes of aging and photoaging. For other disorders, the level of evidence and strength of recommendation are lower, and controlled randomized studies with prolonged follow-ups are necessary in order to assess the clinical usefulness and other potential advantages over current treatment options.

(c) 2020 S. Karger AG, Basel

\section{Introduction}

Topical photodynamic therapy (PDT) is a non-invasive technique based on the sequential application of a photosensitizing drug or a precursor followed by exposure to visible light [1]. Aminolaevulinic acid (ALA) and its methyl ester (methyl-amino-levulinate [MAL]) are the most widely used drugs for PDT in dermatology $[2,3]$. They are approved in European countries and USA for the treatment of actinic keratoses (AKs), in situ squamous cell carcinoma karger@karger.com

(c) 2020 S. Karger AG, Basel

www.karger.com/drm

Karger!
Piergiacomo Calzavara-Pinton

Dermatology Department, University of Brescia

Piazzale Spedali Civili 1

IT-25123 Brescia (Italy)

piergiacomo.calzavarapinton@unibs.it 
(or Bowen disease) and superficial basal cell carcinoma [2]. In addition, PDT has been preliminarily investigated for the treatment of a broad spectrum of cosmetic, inflammatory, and infectious skin conditions [2-5]. Unfortunately, results are not homogeneous and often contrasting, and these discrepancies are not easily understandable although they can be related, at least in part, to the different treatment protocols that have been used [6]. Additionally, the great majority of these studies had a low-quality experimental design, being case reports and uncontrolled studies including a small number of cases [6]. Finally, clinicians without an extended experience in photobiology are sometimes confused by the fact that other photosensitizers (e.g., methylene blue, toluidine blue and other phenothiazines, porphyrin derivatives, and phthalocyanines) have been studied for the same purpose. To clarify the use of PDT in the most commonly investigated non-neoplastic conditions we critically reappraised the most relevant papers of the last 30 years regarding this subject.

\section{Methods of Literature Search}

Studies published from the year 1990 regarding the PDT treatment of photoaging and infectious and inflammatory skin diseases were selected, without language restrictions, from the online databases of PubMed/MEDLINE, Web of Science, and Ovid.

The following keywords were used for the paper search: "photodynamic therapy" OR "photodynamic" OR "PDT" AND "aging" OR "photorejuvenation" OR "hidradenitis suppurativa" or "nevus sebaceous" OR "warts" OR "condyloma" OR "acne" OR "hidradenitis" OR "psoriasis" OR "lichen" OR "leishmaniasis" OR "rosacea" OR "folliculitis" OR "necrobiosis lipoidica" OR "keloids" OR "infections" OR "rosacea" OR "mycosis" OR "lupus". Additionally, two independent reviewers screened titles and abstracts to select potentially relevant articles, and then the chosen full-text papers were analyzed looking for relevant data. We selected randomized controlled clinical trials, non-randomized comparative studies, retrospective studies, and case series studies with a number of at least 10 patients. In the case of clinical indications for which studies with these designs were not available, we evaluated case reports or case series studies enrolling fewer than 10 patients.

The level of evidence and strength of recommendation of PDT were assessed for the most studied clinical indications, according to the EDF/European Centre for Guidelines Development manual [2] (Table 1).

Off-Label Photodynamic Therapy
Table 1. Strength of recommendations and quality of evidence, according to the EDF/European Centre for Guidelines Development manual [2]

Strength of recommendation

A There is good evidence to support the use of the procedure

B There is fair evidence to support the use of the procedure

C There is poor evidence to support the use of the procedure

D There is fair evidence to support the rejection of the use of the procedure

E There is no evidence to support the rejection of the use of the procedure

Quality of evidence

I Evidence obtained from at least one properly designed, randomized controlled trial

II-i Evidence obtained from well-designed controlled trials without randomization

II-ii Evidence obtained from well-designed cohort or casecontrol analytical studies, preferably from more than one center or research group

II-iii Evidence obtained from multiple time series with or without the intervention; dramatic results in uncontrolled experiments (such as the results of the introduction of penicillin treatment in the 1940s) could also be regarded as this type of evidence

III Opinions of respected authorities based on clinical experience, descriptive studies, or reports of expert committees

IV Evidence inadequate owing to problems of methodology (e.g. sample size, length of comprehensiveness of followup, or conflicts in evidence)

\section{Fundamentals of PDT}

\section{Photosensitizers}

In Europe, four topical drug preparations are approved for PDT: Metvix ${ }^{\circledR}$ cream and Luxera ${ }^{\circledR}$ cream (Galderma, Paris, France) containing $160 \mathrm{mg} \mathrm{MAL/g}$, Ameluz ${ }^{\circledR}$ gel (Biofrontera, Leverkusen, Germany) containing $78 \mathrm{mg}$ of $\mathrm{ALA} / \mathrm{g}$ in a nano-emulsion, and a $4-\mathrm{cm}^{2}$ patch containing 8 mg of ALA (Alacare ${ }^{\circledR}$; Galderma). A 20\% ALA solution (Levulan Kerastick, DUSA Pharmaceuticals, MA, USA) is available in the USA and Canada but not in Europe. In addition, a number of medical devices with various ALA concentrations and formulations are self-produced in clinical centers or are available on the market, although not being formally approved by the authorities.

Unlike ALA, MAL has a methyl ester group that makes it more lipophilic, thus enhancing its penetration into cells and its tumor selectivity $[1,2,7]$. Upon cell penetration MAL is immediately demethylated to ALA, and 
therefore the intracellular chemical and biochemical profile of the two compounds is the same. ALA is not photochemically reactive "per se" but it is quickly metabolized to protoporphyrin IX (PpIX) by the enzymes of the heme biosynthetic pathway, and afterwards PpIX accumulates in the cell because the next biochemical step, the iron chelation to heme, can take up to some hours $[1,2,7]$.

Photoactivation of PpIX produces singlet oxygen $\left({ }^{1} \mathrm{O}_{2}\right)$ and other reactive oxygen species, such as superoxide anion, hydrogen peroxide, and hydroxyl radical, causing oxidative damage to nucleic acids, proteins, and lipids. According to the entity of the damage, either pro- or anti-inflammatory cellular pathways are activated, as well as either necrotic or apoptotic cascades. This sequence of events happens in all cell populations of epidermal and dermal compartments and in cells trafficking in the skin, including immuno cells, thus giving PDT an immunemodulatory effect as well $[1-4,7]$.

The variety of mechanisms involved in this process allows different combinations of drugs and light to act and modulate the process at different steps of the cycle, therefore obtaining a wide spectrum of possible results; this is the rationale behind the use of PDT for such a broad number of clinical indications [1].

Synthetic photosensitizers with a tetrapyrrolic chemical structure (i.e., benzoporphyrins, chlorins, and phthalocyanines, as well as phenothiazines - methylene blue and toluidine blue) are currently under laboratory and clinical investigation. After topical application, they have a poor capacity of penetration into the skin, and therefore they are of poor interest for the treatment of tumoral and inflammatory disorders. However, their use against microbial infections seems particularly promising as they can effectively sensitize microorganisms without harming skin cells [1].

\section{Light Sources and Dosimetry}

Both natural and artificial light sources can be used for PDT, provided that their emission spectrum matches, at least partially, the absorption spectrum of the photosensitizer, and the irradiance is enough to allow a reasonable duration of exposure. However, the irradiance must be lower than $100-150 \mathrm{~mW} / \mathrm{cm}^{2}$, in order to avoid a photothermal effect. Finally, the size and the uniformity of the irradiation field are critical issues for a successful treatment as well [1].

As the PpIX absorption spectrum covers the whole visible range, many light sources are suitable for MAL/ALA PDT. These generally emit the whole visible spectrum or selective wavebands matching only the strong absorption peak (B-band) at $406 \mathrm{~nm}$, or the other four minor (20-40 lower) peaks (the Q-bands) at 506, 542, 577, and $630 \mathrm{~nm}$ [8]. Longer wavelengths penetrate deeper into the skin, therefore light sources with an emission peak at $630 \mathrm{~nm}$ are preferred to treat thicker epidermal or dermal lesions $[9,10]$, whereas white light and red light seem equally effective when treating superficial epidermal lesions [2].

Light sources emitting in the whole visible spectrum are natural sunlight (provided that the ultraviolet emission has been filtered with a sunscreen), fluorescent lamps, metal halide lamps, and broad-band light-emitting diodes (LEDs). Lamps emitting selected wavebands are defined as coherent (e.g., lasers, particularly the dye laser) and non-coherent (e.g., intense pulsed light [IPL], selected fluorescent lamps, filtered metal halide lamps, and narrow-band LEDs).

Careful dosimetry of light fluence is recommended, but spectroradiometers are expensive, difficult to use, and time consuming. Broad-band radiometers for visible light are more practical, but they are expensive as well and need frequent calibration. However, fortunately, in the daily clinical activity, only the first measurement is mandatory (and it is usually already done by the manufacturing company), and a frequent measurement of output is not needed because light sources emitting visible light are usually quite stable for a long time [1].

\section{Off-Label Cosmetic Indications}

A possible use of ALA/MAL PDT for aesthetic purpose is photorejuvenation, i.e., the improvement of selected clinical features of facial skin aging with aesthetic relevance [6].

Indeed, several studies with various experimental designs and different treatment protocols have shown a significant improvement of fine wrinkles, mottled hyperpigmentation, sallowness, skin texture, tactile roughness, telangiectasias, and diffuse erythema, as well as of the Glogau global score for photoaging [2-5, 7, 9-11].

Even a short-time $(1-3 \mathrm{~h})$ application, without occlusion, of a $20 \%$ ALA solution followed by exposure to blue light $[12,13]$ improved skin texture [13], global skin quality, fine wrinkling, and sallowness [12], although showing a mild [12] or poor [13] improvement in mottled hyperpigmentation and no changes in coarse wrinkles $[12,13]$. A few case series studies investigated PDT with IPL devices [14-20]. In comparison to continuous red light sources, IPLs allowed significantly shorter duration of exposure and were less painful, therefore being preferred by 

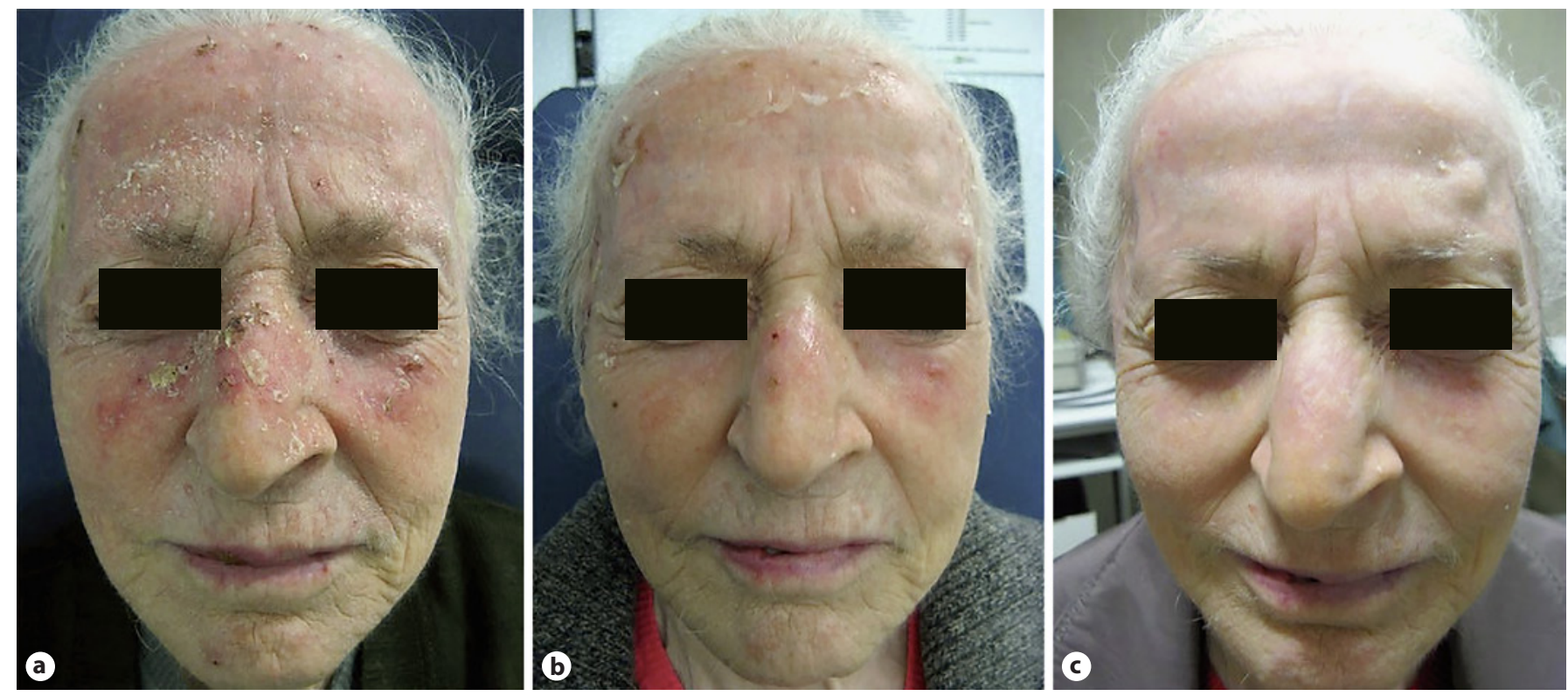

Fig. 1. Effect of PDT on multiple actinic keratoses of the face with photorejuvenation of the surrounding skin before (a), during (b), and after (c) treatment.

patients, particularly if broad areas (i.e., the whole face) were treated [21]. In split-face comparison studies, ALAIPL PDT was more effective than IPL alone for the improvement of coarse wrinkles [22], fine lines [22, 23], mottled hyperpigmentation [23, 24], crow's feet [24], tactile roughness [24], and telangiectasias [24], without differing significantly in the degree of inflammation. The improvement of the overall cosmetic appearance of mildto-moderate facial photodamage (as rated by both investigators and patients) was also achieved in 10 women treated with 3 sessions, at 30-day intervals, with hexyl ALA and IPL [25].

Although a number of studies on this matter can be found in the literature, the optimal IPL-PDT protocol is still unknown because the considered parameters (IPL wavelength, pulse duration, pulse interval, and energy density, and the ALA application time, formulation, and concentrations - from 0.5 to $20 \%$ ) were often different.

Combined treatment protocols and new techniques to maximize trans-epidermal ALA penetration have been investigated in order to improve the efficacy of PDT. In a study including 21 patients, several passes with a microneedle (0.3-mm length) roller before a 1-h ALA application, combined with a double exposure to red light and IPL, gave excellent results. In a pilot split-face study, MAL-PDT combined with microneedles (1.5-mm length), it was shown that the combination had superior cosmetic results in comparison to standard MAL-PDT [26]. Although the results were good, adverse effects such as erythema, edema, crusting, and pain were significantly more frequent and intense with microneedles-PDT, and AK clearance rates were not different [26]. A split-face study of 4 patients found that fractional resurfacing followed by MAL-PDT improved fine wrinkles significantly more than MAL-PDT alone [27].

Two double-blind randomized trials investigated not only clinical but also histological changes $[28,29]$ of conventional MAL-PDT (MAL cream was applied under occlusion for 2-3 h before exposure to red light) versus red light alone, and the results showed that the former was significantly more effective in improving the global score of facial photodamage and all specific clinical variables, excluding telangiectasia [28]. Additionally, they showed that, at a histological level, there was an increase of functional dermal collagen and elastic fibers, coupled with a decrease of perifollicular fibrosis [29]. Subsequent studies demonstrated a reduction of epidermal thickness, dermal inflammatory and elastotic material in the dermis, and an increase of expression of procollagen type I and III [30, 31]. The positive changes of the dermal matrix were found to be more consistent after serial PDT sessions rather than after a single exposure, suggesting that repeated treatments lead to better and more stable clinical improvement [32]. High-resolution sonography was used 
for non-invasive imaging of PDT effects, and it showed an increase of dermal thickness with a concurrent thinning of the subepidermal band of elastotic material [33].

Finally, aesthetic manifestations of chronic severe photodamage are often accompanied by the presence of the so-called field of cancerization, where multiple AKs are present and apparently normal keratinocytes of the surrounding skin harbor severe, UV-related, molecular DNA damages. Of great interest is the fact that PDT was effective not only against aesthetic changes of aging but also against the molecular damage present in the field of cancerization [6]. Therefore, PDT of chronically photodamaged patients with multiple AKs has at the same time a healing effect for AKs, a photorejuvenative effect with an aesthetic significance (Fig. 1) as well as a tumor-preventative potential.

\section{Disorders of the Pilosebaceous Unit}

Acne is a very frequent skin disease affecting approximately $85 \%$ of people aged $12-25$ years [34]. Incidence decreases in adulthood, but $26 \%$ of women in their 40 s still report the disease [35].

It is a disorder of the pilosebaceous unit caused by the interplay of different pathogenetic causes [36]. PDT has been demonstrated to reduce the activity of the sebaceous gland and normalize the follicular hyperkeratosis $[3,37-$ 42]. In addition, Propionibacterium acnes contains the enzymatic machinery for the metabolization of ALA to endogenous fluorescent porphyrins $[3,37]$, and the intensity of fluorescence is related to the degree of $P$. acnes colonization $[3,38]$. However, it is still debated whether clinical improvement correlates with a decrease of this colonization $[38,41]$.

Several studies have reported that ALA/MAL PDT is effective against acne [2, 3]. As early as 2000, Hongcharu et al. [38] treated three areas of the back of 22 acne subjects with multiple sessions of ALA plus red light, ALA alone, and red light alone, with a fourth area left untreated. They observed that clinical and histological improvement of inflammatory acne after 20 weeks was significantly better with ALA-PDT. A split-face comparative study of 20 patients showed that 4 sessions of ALA-PDT with blue light was superior to blue light alone in the reduction of both inflammatory and non-inflammatory lesions in patients with moderate-to-severe acne vulgaris, but the difference was not statistically significant [39]. A retrospective multicenter Italian observational study using MAL-PDT (average incubation of 3-4 h followed by illumination with
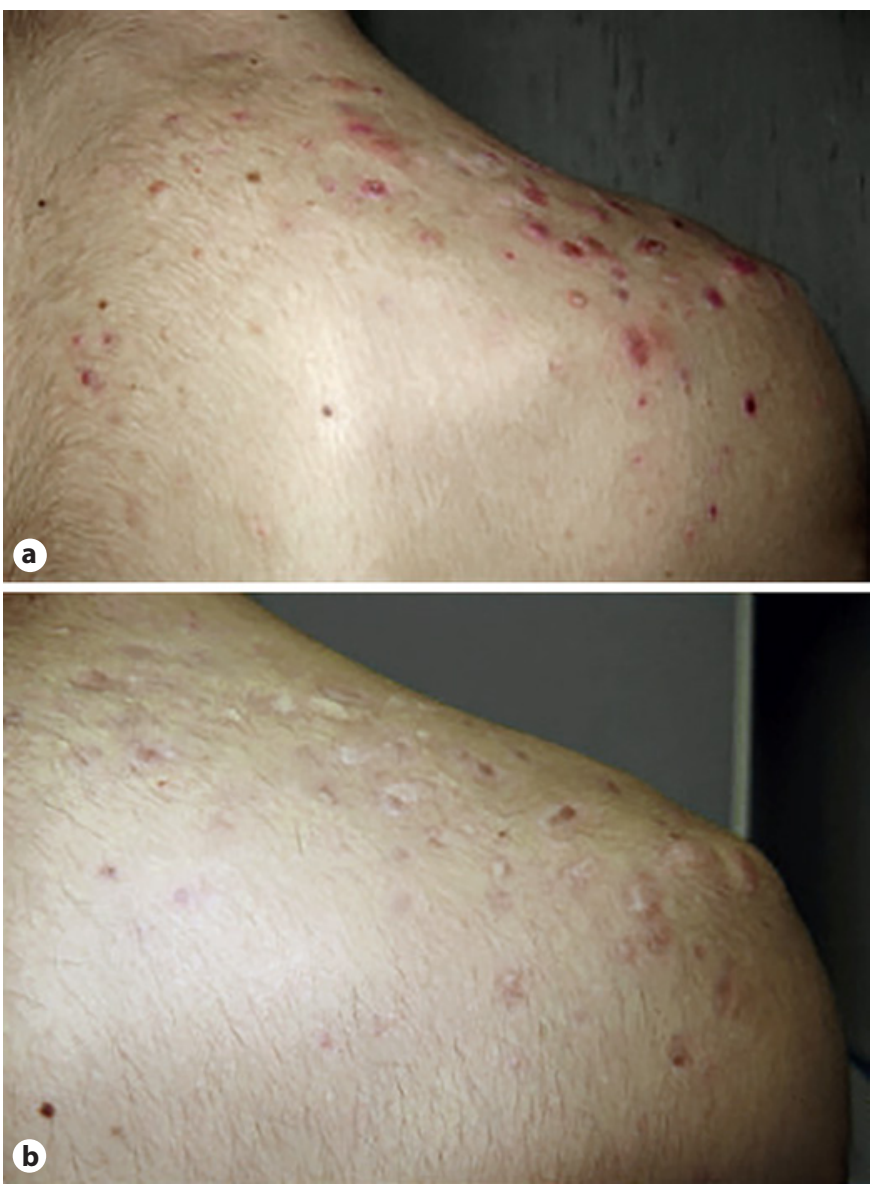

Fig. 2. Photodynamic therapy of severe papulopustular acne of the right shoulder before (a) and after (b) treatment.

red light at $37 \mathrm{~J} / \mathrm{cm}^{2}$ ), of 92 acne patients who received a mean number of 3.3 sessions with a mean of 19.6 days of interval between treatments, reported $>75 \%$ improvement in $72.8 \%$ of patients (Fig. 2) [4]. A double-blind, randomized, vehicle-controlled multicenter trial of $153 \mathrm{pa}-$ tients with severe facial acne showed that 12 weeks after a cycle of 4 treatments (each performed 2 weeks apart from the previous one) with MAL-PDT ( $1.5 \mathrm{~h}$ of incubation followed by exposure to $37 \mathrm{~J} / \mathrm{cm}^{2}$ of red light) significantly reduced the inflammatory lesion count, in comparison to PDT with the vehicle alone [43]. Recently, a randomized controlled study involving 46 patients with moderately severe inflammatory acne found that 2 PDT sessions (ALA $20 \%$ cream under occlusion for $1.5 \mathrm{~h}$ before irradiation with $37 \mathrm{~J} / \mathrm{cm}^{2}$ of red light) at a 2-week interval was more effective than the combination of doxycycline and adapalene gel [44]. Several other studies (split-face comparison, prospective studies, randomized clinical trials) using 5-20\% ALA and red light exposure reported clinical im- 


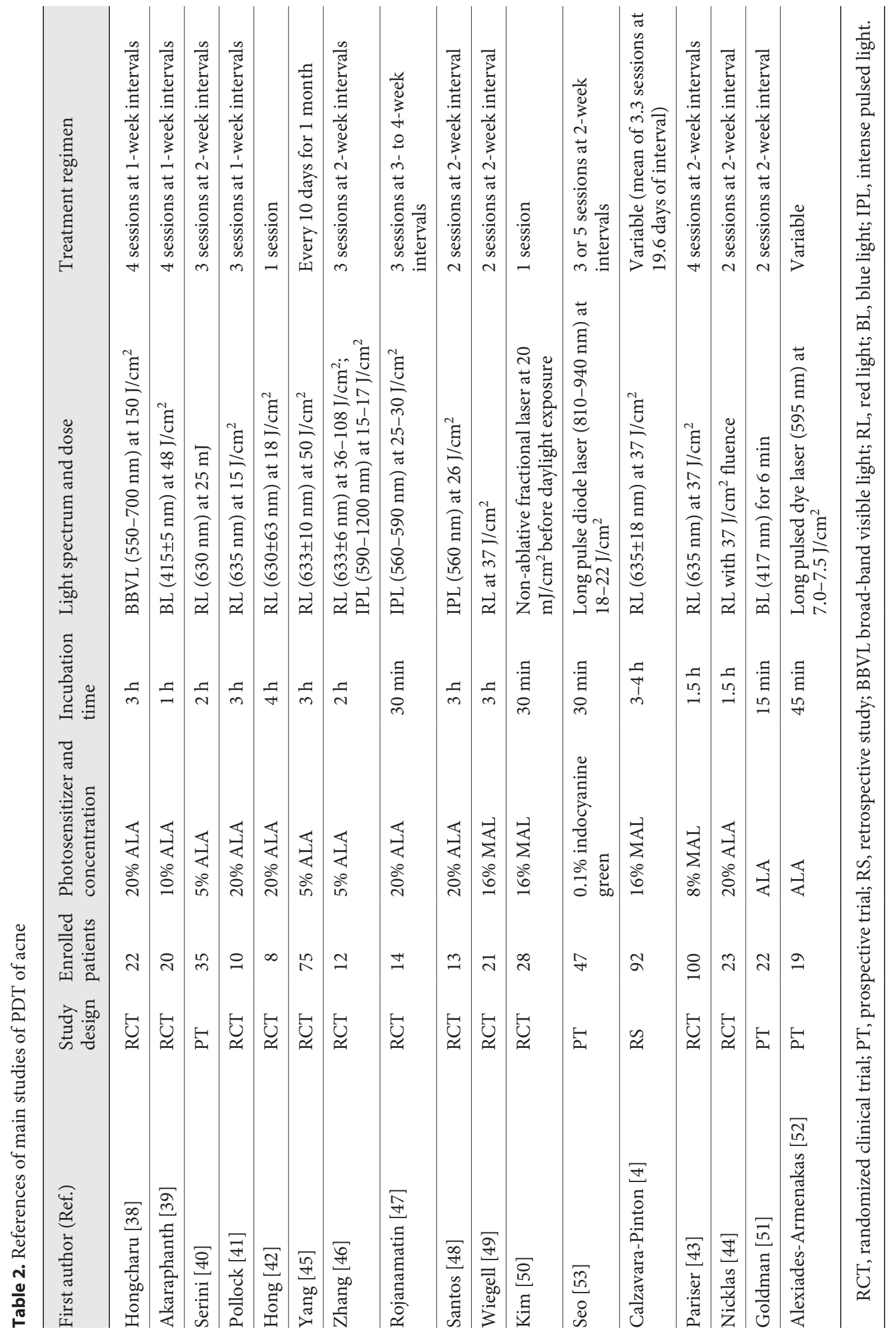


provement of inflammatory lesions of mild-to-moderate acne vulgaris without significant adverse effects [40-42]. In an open, prospective, parallel-arm trial of 75 patients with facial conglobate acne, 3 sessions (10 days apart) of $5 \%$ ALA-PDT were found to be more effective in reducing scar formation than red light and a Chinese herbal medicine mask [45]. Taken together, these studies emphasize the therapeutic potential of PDT with exposure to continuous light sources against acne, and that adverse effects are uncommon and generally limited to transitory inflammation and pain, with rare cases of persistent dyspigmentation of the treated area [38].

A comparison split-face study between ALA-PDT with red light and ALA-PDT with IPL concluded that the former was statistically more effective, whereas the latter had less adverse reactions and better tolerability [46]. In other studies, results with ALA- or MAL-PDT with IPL were conflicting and varied from beneficial effects in inflammatory lesions in a pilot trial [47] to no apparent clinical improvement in two randomized clinical trials $[48,49]$. A randomized comparative trial with MAL-PDT and fractional laser-assisted daylight irradiation showed disappointing clinical results for inflammatory acne and relevant skin toxicity with pain, discomfort, and local inflammation [50]. Perhaps through a synergy of thermal effects and photodynamic effects, multiple treatments with short-time (30-60 min) 20\% ALA application followed by continuous-wave blue light or pulsed dye laser improved inflammatory acne with few short-term adverse effects and good tolerability $[51,52]$. The use of indocyanine green as photosensitizer was investigated in a clinical trial [53] with partial but promising results, and further studies are desirable to explore more in depth this treatment modality. The main results of papers on PDT treatment in acne are summarized in Table 2.

Application of ALA- or MAL-PDT and different light sources to other disorders of the pilosebaceous unit has also been explored. A substantial, albeit transitory, improvement was seen in the majority of 17 rosacea patients treated with MAL-PDT [54]. PDT with intralesional ALA injections was proposed as an alternative option for localized hidradenitis suppurativa [55], and a randomized clinical trial with methylene blue activated with IPL reported successful and promising results [56]. PDT was also used to treat nevus sebaceous of the face showing mild (25\%), moderate (58\%), and marked (17\%) improvement in all 12 patients [57]. Finally, a prospective study demonstrated the clinical improvement of folliculitis decalvans after 4 sessions of MAL-PDT in 9 out of 10 patients [58].

\section{Inflammatory Skin Diseases}

When ALA-PDT took its first steps in dermatology, psoriasis was considered one of the main potential indications because ALA accumulates to a greater extent in psoriatic plaques than in normal surrounding skin and inflammatory T lymphocytes are highly sensitive to PDTinduced apoptosis [1]. Indeed, immunohistochemical investigations of psoriatic lesions treated with PDT showed normalization of epidermal proliferation and differentiation, decreased infiltration of pathogenetically relevant T-cell subsets [59], and reduced dermal neovascularization [60]. However, clinical results have been disappointing with limited and unpredictable clinical response and significant pain, stinging, and burning during and after irradiation is frequent [60-64]. In addition, costs could most often be excessive because psoriatic lesions may cover a large part of the body surface and clearing of lesions, if any, is seen after repeated treatments.

Recently, PDT has been suggested as a new treatment option for oral lichen planus. In various randomized controlled trials [65-68], toluidine blue-mediated PDT significantly reduced inflammation and pain, but the comparison of efficacy with conventional topical corticosteroids has shown conflicting results. A randomized trial of 40 women with genital erosive lichen planus showed that efficacy and tolerability of one session of PDT with hexyl 5-aminolevulinate-hydrocloride (HAL) and daily applications of clobetasol propionate $0.05 \%$ ointment for 6 weeks were not statistically different, but authors emphasized that, unlike clobetasol, PDT does not have the hazards of long-term toxicity [69].

PDT has also been investigated in the treatment of genital lichen sclerosus, another chronic inflammatory disease with the need of safe and effective alternatives to topical corticosteroids [70-78]. In several studies of small case series, 1-4 sessions of ALA-PDT induced a complete or partial clinical remission in most patients with a symptomatic relief, and they were always well tolerated [7075], and a randomized controlled clinical trial of $40 \mathrm{pa}-$ tients reported that 4 sessions of ALA-PDT at 2-week intervals were more effective than the daily application of clobetasol propionate ointment for 8 weeks [76]. Since therapy with red light could be connected with local pain during illumination, a case series study of 11 patients [78] evaluated the efficacy and tolerability of ALA-PDT with green light and reported a very good tolerability, an improvement of local status, and a reduction of pruritus.

The improvement of lichen sclerosus with PDT is accompanied by a reduction of expression of molecular 
Fig. 3. Chronic cutaneous lupus erythematosus of the scalp before (a) and after (b) 10 weekly sessions of MAL-PDT.
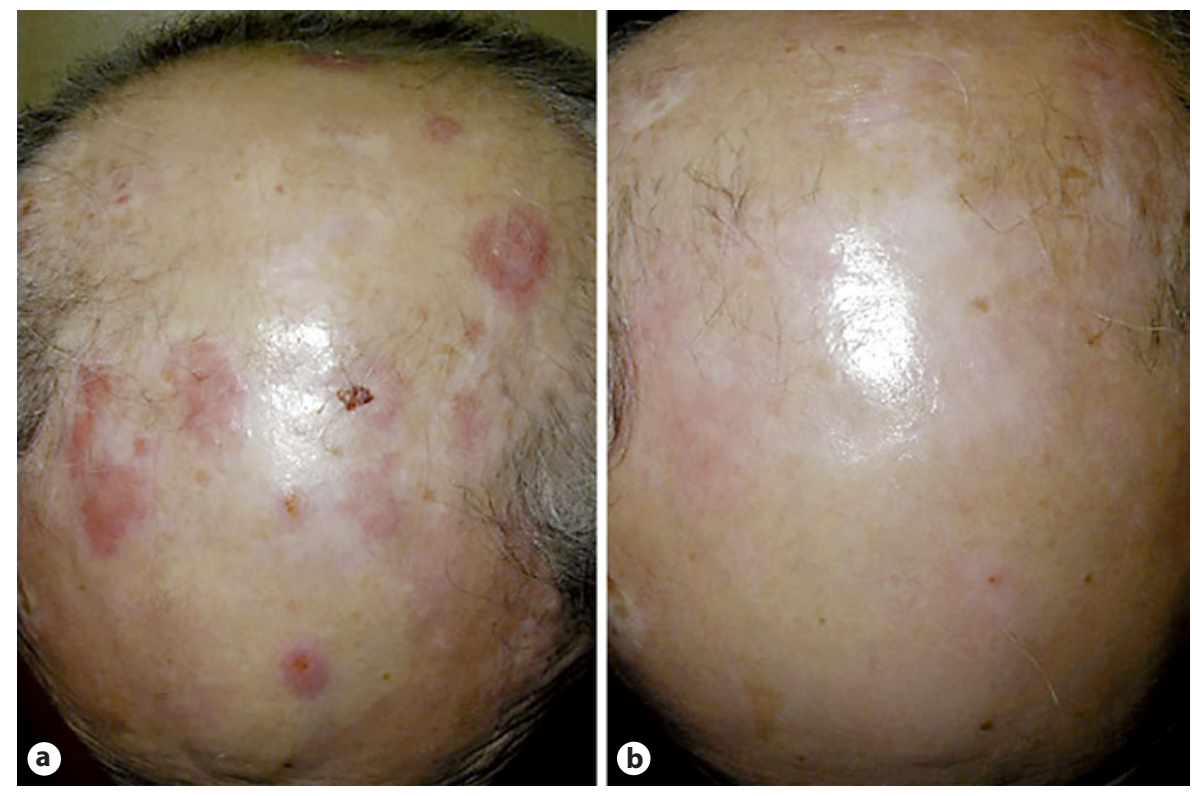

markers of vascularization (CD34), nervous cell function (myelin basic protein), keratinocytes function (CD44), and proliferation index (Ki-67) [77].

An uncontrolled study of 5 patients with localized scleroderma showed a reduction of clinical score and an improvement of the durometer score after once- or twiceweekly sessions (for 3-6 weeks) with the application of $3 \%$ ALA gel followed by irradiation with an incoherent lamp [79]; the only adverse effect was a transient hyperpigmentation [79]. These results were challenged by another study (a single-blind, prospective, comparative trial with intraindividual controls enrolling 6 patients) that reported a poor efficacy, although it confirmed that safety and tolerability were very good [80]. A study of 20 patients without controls reported a beneficial persistent effect of 3 MAL-PDT sessions against keloids, which appeared to be due to a decrease of collagen synthesis and neovascularization [81].

To date, only few case reports have described the improvement or remission of discoid lupus erythematosus lesions of the face, neck, and scalp, following weekly sessions of MAL-PDT and 6-monthly maintenance treatments [82-84]. We also successfully treated an LED patient with 10 weekly sessions of MAL-PDT (Fig. 3). However, 2 patients with recalcitrant discoid lupus erythematosus of the face who were treated with 3 and 2 sessions of ALA-PDT, respectively, showed no clinical improvement and a bad tolerance to the therapy [85].

Another dermal disease that has attracted the attention of researchers is necrobiosis lipoidica. A retrospec- tive study of 18 patients reported a $40 \%$ complete clearance rate with conventional MAL- or ALA-PDT [86], and another retrospective study of 65 patients reported a complete clearance in $64 \%$ (45/70 patients) with conventional MAL-PDT and 80\% (8/10) with daylight PDT [87].

\section{Skin Infections}

ALA has a high affinity for human papilloma virusinfected keratinocytes and, after ALA application, a higher fluorescence is detected in genital warts in comparison to the normal surrounding skin [88]. In pilot studies of small case series, the cure rates of repetitive sessions (up to 6 times) of ALA-PDT with white $[89,90]$ or red [9193] light were very high, ranging from 50 to $100 \%$, without recurrences after follow-ups of at least 4 months and a good cosmetic outcome [89-93]. Aiming to clarify the optimal light source for PDT of warts, a randomized study including 30 patients with a total of 250 recalcitrant hand and foot warts, compared ALA-PDT with white, blue, and red lights. PDT with white light was significantly more effective than PDT with red and blue lights and also more effective than cryotherapy [90]. In a randomized, double-blind clinical trial of ALA-PDT versus placebo PDT for 232 recalcitrant foot and hand warts of 45 patients, the median relative reduction in the wart area was $98 \%$ with ALA-PDT versus 52\% with placebo after 14 weeks and $100 \%$ versus $71 \%$ after 18 weeks [94]. Conventional treatments of subungual and periungual warts are 
often ineffective, but a pilot study of patients with a total of 40 lesions reported that ALA-PDT was effective with a $100 \%$ complete clearance in $90 \%$ of patients after a mean of 4.5 treatments [95].

The above-mentioned studies had some relevant differences in the treatment protocols, and we could not find comparative studies to establish the ideal one. However, recent findings have demonstrated that shaving or careful surgical paring of the hyperkeratosis should always precede ALA application because they can facilitate its penetration into the skin $[96,97]$.

Pain and transient hyperpigmentation are the only adverse effects of PDT for warts. However, pain during and after (up to $24 \mathrm{~h}$ ) light exposure is described as severe or unbearable by about $20 \%$ of patients $[94,95,98,99]$ and, unfortunately, effective methods to decrease it have not been suggested so far.

The use of methylene blue as a photosensitizer for PDT of warts has been investigated as well. In a randomized double-blind placebo-controlled study, plane warts were successfully treated with daylight PDT with topical 10\% methylene blue gel. Unlike ALA/MAL PDT the treatment was almost painless [98], and we emphasize that it is also much cheaper.

Several clinical trials have reported beneficial effects of topical PDT for the treatment of genital warts: ALA-PDT appeared to be as effective as $\mathrm{CO}_{2}$ laser evaporation for vulvar condylomata [100] and as $\mathrm{CO}_{2}$ laser evaporation or surgical excision for vulvar and vaginal condylomata with intraepithelial neoplasia grade III [101]. Additionally, PDT showed a shorter healing time, excellent cosmetic results, and minimal tissue destruction [100, 101]. A case series study of 12 patients demonstrated that ALAPDT is also effective for condylomata of males, and 2 sessions of ALA-PDT 1 week apart showed an overall cure rate of $72.9 \%$ after 12 months from the end of treatment, with minimal side effects during the irradiation [102]. A following randomized study of 65 males again did not find differences of efficacy between ALA-PDT and $\mathrm{CO}_{2}$ laser evaporation, but the recurrence rate (6.3 vs. $19.1 \%$ ) and the proportion of patients with adverse effects (13.9 vs. $100 \%$ ) were significantly lower with ALA-PDT [103]. Another randomized trial with 91 patients confirmed that ALA-PDT was as effective as conventional $\mathrm{CO}_{2}$ laser evaporation but with a lower incidence of adverse effects and recurrence rate [104].

ALA-PDT was also found to be effective for the treatment of urethral condylomata acuminata of 191 patients of both sexes provided that light was delivered through an intraurethral cylindrical fiber [105]. Histological exami- nation with light microscopy and electron microscopy of treated lesions showed both apoptosis and necrosis of HPV-infected keratinocytes [105]. Recently, the clinical effects of the combination of $\mathrm{CO}_{2}$ laser ablation followed by 3 times ALA-PDT were investigated in a single-arm prospective study of 98 cases of both sexes. Three months after the treatment, $93.8 \%$ of patients showed complete cure of the treated area, but 18 patients showed new lesions in the surrounding skin [106]. These results were challenged by a following phase III prospective randomized double-blind study of 175 patients that reported that adjuvant ALA-PDT of condylomata acuminata after $\mathrm{CO}_{2}$ laser ablation did not help in preventing recurrence of anogenital warts [107]. A randomized controlled trial of 141 patients was undertaken in order to assess the best method to increase the tolerability of ALA-PDT of genital warts, and a two-step irradiance schedule reduced more significantly the patients' pain degree in comparison to single-dose cold compress [108].

Another successful indication of PDT is cutaneous infection by both Leishmania major and L. tropica. In a controlled randomized trial of 60 patients suffering from cutaneous leishmaniasis caused by L. major, 4 weeks of therapy with a weekly treatment with $10 \%$ ALA-PDT, twice daily topical paromomycin, or twice daily placebo led to clearance of lesions in 93.5, 41, and 13\% of cases, respectively, after 3 months of follow-up [109]. Furthermore, none of the patients in the PDT group showed deep and disfiguring scars, whereas scarring developed in $42 \%$ of patients treated with paromomycin and in $11 \%$ of patients treated with placebo [109]. Only slight hypopigmentation in the irradiated area was observed in a case report where the patient was successfully treated with MAL-PDT [110]. In addition to these randomized controlled trials, there are several studies of case series with similar clinical results although they used different treatment protocols (ALA applied under occlusion for $4 \mathrm{~h}$ or MAL for $3 \mathrm{~h}$; 1-5 weekly treatment sessions). Response rates ranged from 96.9 to $100 \%$, tolerability was always very good, cosmetic results were always excellent, and recurrences were never seen during the 1- to 6-month follow-up periods [111-114]. In comparison to cryotherapy, ALA-PDT resulted in being equally effective, but cosmetic results were better, whereas pain was more intense [115]. The place of PDT in the therapeutic armamentarium against leishmaniasis is still debated, although the technique seems particularly valuable for the treatment of lesions in aesthetically sensitive sites and for lesions resistant to other methods of treatment [2]. The mechanisms underlying the sterilizing effect of PDT on leishmaniasis 
Table 3. Summary of recommendations for ALA/MAL PDT use for non-neoplastic skin conditions [2]

\begin{tabular}{lll}
\hline $\begin{array}{l}\text { Strength of } \\
\text { recommendation }\end{array}$ & $\begin{array}{l}\text { Quality of } \\
\text { Evidence }\end{array}$ & Indication \\
\hline A & I & $\begin{array}{l}\text { Skin aging } \\
\text { Acne } \\
\text { Refractory hand/foot warts } \\
\text { Refractory genital warts } \\
\text { Cutaneous leishmaniasis }\end{array}$ \\
& I & Keloids \\
& & $\begin{array}{l}\text { Lichen sclerosus } \\
\text { Sebaceous gland hyperplasia } \\
\text { Psoriasis } \\
\text { C }\end{array}$ \\
C & III & Rosacea \\
D & I & Necrobiosis lipoidica \\
D & III & \\
\hline
\end{tabular}

are not well understood. The yield of singlet oxygen by PpIX photoactivation was thought to have a toxic killing effect on Leishmania spp [113]. However, in vitro studies did not demonstrate any parasiticidal effects of PDT on amastigotes, and the clearance of cutaneous lesions after irradiation appeared to occur through a systemic immune response of the host [116]. Some species of leishmania that can cause mucocutaneous (L. braziliensis complex) or visceral leishmaniasis (L. donovani complex) have a metabolic defect in the biosynthesis of heme and therefore they should not be treated with PDT [117].

PDT showed bactericidal activity as well. Two weekly sessions of ALA-PDT were more effective than 2 sessions with red light alone in reducing the bacterial load and in promoting the healing of bilateral chronic skin ulcers infected with Pseudomonas aeruginosa in 26 patients [118].

Erythrasma is a superficial cutaneous infection caused by Corynebacterium minutissimum that has a naturally high content of endogenous porphyrins. Red light irradiation without exogenous photosensitizing molecules improved erythrasma of 13 patients [119].

Results of experimental investigations have demonstrated that dermatophytes and yeasts can be effectively sensitized in vitro by a number of photosensitizers including phenothiazine dyes, porphyrin derivatives, and phthalocyanines, as well as ALA/MAL [120]. Onychomycosis has been the most investigated clinical indication for this, mainly because of the limitations of the current topical and oral drug treatments [121-127]. Two randomized controlled trials showed that 12 sessions (a session every 15 days for 6 months) of PDT with methylene blue (2\%) were significantly more effective than oral fluconazole (300 mg/ week for 6 months) [121], whereas 8 sessions (a session every 15 days for 4 months) were as effective as 8 sessions of irradiation with IPL in the treatment of onychomycosis of the toenails [122]. The complete clearance rates with methylene blue PDT were 90 and $70 \%$, respectively [121, 122]. Results of smaller uncontrolled studies with methylene blue were rather superimposable $[123,124]$. PDT with a nano-emulsion of aluminium-phthalocyanine chloride effectively treated $60 \%$ of onychomycosis of 20 patients [125]. Effectiveness and safety were similar to the conventional treatments, with the advantage of the absence of collateral effects and the possibility to repeat the treatment without inducing fungal resistance [125].

In a case series study of 30 patients with toenail infection by Trichophyton rubrum treated with ALA-PDT (3 sessions with 2 -week intervals) the cure rates were $43.3 \%$ after 12 months and $36.6 \%$ after 18 months [126]. Interestingly, a randomized controlled trial compared 3 sessions of MAL-PDT versus red light alone for onychomycosis. The comparison of overall remission rates did not show significant differences, but MAL-PDT resulted in better rates of clinical and microbiological response in non-dystrophic versus dystrophic onychomycosis patients [127]. In this and other previous studies, a pretreatment with $40 \%$ urea was used to soften the nail plate in order to increase the penetration of the photosensitizer [122, 126, 127]. Although antifungal PDT has been mainly investigated in the treatment of onychomycosis, its clinical applications for the treatment of other fungal infections were also evaluated [128-130]. Methylene blue-PDT showed promising results in patients with chromoblastomycosis [128] and sporotrichosis [131]. PDT with a porphyrin derivative was effective in the treatment of denture stomatitis [129], and PDT with ALA/MAL and various phenothiazine dyes was considered a potential approach for the treatment of antimycotic drug-refractory oral candidiasis in normal people [132] and HIV-infected patients [130].

MAL-PDT showed some efficacy against skin mycoses in immunocompetent subjects as well, but it did not seem to ensure clinical advantages over similarly effective and much cheaper topical drug treatments [133].

\section{Conclusion}

Despite a history of experimental and clinical use of more than 100 years, PDT is only now starting to be appreciated for its full potential. Particularly in the past 30 years, we have greatly improved the knowledge of PDT effects in human normal and pathological skin [3]. The broad spectrum of biochemical and pathological effects 
has prompted its application for various cosmetic, inflammatory, and infectious conditions with variable success rates. Everything considered, we have enough evidence to state that MAL- and ALA-PDT may be an effective treatment option for a number of conditions, such as skin aging, acne, warts, condylomata, and Leishmania skin infection (Table 3). For other disorders, the level of evidence and strength of recommendation are lower, and large controlled studies with prolonged follow-ups are necessary in order to assess the full therapeutic potential and all its possible applications. Finally, the desirable availability of new photosensitizers, currently under preclinical and/or early clinical investigation, with better photochemical properties than PpIX, could induce a new impulse to the clinical interest for this treatment modality [2].

\section{Key Message}

We review the off-label use of photodynamic therapy for the treatment of cosmetic, infectious, and inflammatory skin conditions.

\section{Disclosure Statement}

The authors have no conflicts of interest to declare.

\section{Funding Sources}

The authors have no funding sources to declare.

\section{Author Contributions}

Giuseppe Monfrecola: contributions to the design of the work, to acquisition and analysis of data for the work, and to drafting the work. Matteo Megna and Gabriella Fabbrocini: contributions to the conception or design of the work, to analysis of data for the work, and to drafting the work. Chiara Rovati and Mariateresa Rossi: contributions to acquisition of data for the work and to drafting the work. Mariachiara Arisi: contributions to analysis of data for the work and to drafting the work. Irene Calzavara-Pinton: contributions to drafting the work and to its linguistic correction. Piergiacomo Calzavara-Pinton: contributions to the conception or design of the work, to acquisition and analysis of data for the work, and to drafting the work.

\section{References}

1 Calzavara-Pinton PG, Venturini M, Sala R. Photodynamic therapy: update 2006. Part 1: Photochemistry and photobiology. J Eur Acad Dermatol Venereol. 2007 Mar;21(3): 293-302.

2 Morton CA, Szeimies RM, Basset-Seguin N, Calzavara-Pinton P, Gilaberte Y, Haedersdal $M$, et al. European Dermatology Forum guidelines on topical photodynamic therapy 2019 Part 1: treatment delivery and established indications - actinic keratoses, Bowen's disease and basal cell carcinomas. J Eur Acad Dermatol Venereol. 2019 Dec;33(12):2225-38.

3 Megna M, Fabbrocini G, Marasca C, Monfrecola G. Photodynamic Therapy and Skin Appendage Disorders: A Review. Skin Appendage Disord. 2017 Jan;2(3-4):166-76.

4 Calzavara-Pinton PG, Rossi MT, Aronson E, Sala R. Italian Group for Photodynamic Therapy: A retrospective analysis of real-life practice of off-label photodynamic therapy using methyl aminolevulinate [MAL-PDT] in 20 Italian dermatology departments. Part 1: Inflammatory and aesthetic indications. Photochem Photobiol Sci. 2013;12:148-57.

5 Calzavara-Pinton PG, Rossi MT, Sala R; Italian Group For Photodynamic Therapy. A retrospective analysis of real-life practice of offlabel photodynamic therapy using methyl aminolevulinate (MAL-PDT) in 20 Italian dermatology departments. Part 2: oncologic and infectious indications. Photochem Photobiol Sci. 2013 Jan;12(1):158-65.

6 Morton CA, Szeimies RM, Basset-Séguin N, Calzavara-Pinton PG, Gilaberte Y, Haeders- dal M, et al. European Dermatology Forum guidelines on topical photodynamic therapy 2019 Part 2: emerging indications - field cancerization, photorejuvenation and inflammatory/infective dermatoses. J Eur Acad Dermatol Venereol. 2020 Jan;34(1):17-29.

7 Ortel B, Shea CR, Calzavara-Pinton P. Molecular mechanisms of photodynamic therapy. Front Biosci. 2009 Jan;14(14):4157-72.

8 Rossetti FC, Depieri L, Tedesco AC, Lopes Badra Bentley MV. Fluorometric quantification of protoporphyrin IX in biological skin samples from in vitro penetration/permeation studies. Braz J Pharm Sci. 2010;46(4):753-60.

9 Dirschka T, Radny P, Dominicus R, Mensing H, Brüning H, Jenne L, et al.; AK-CT002 Study Group. Photodynamic therapy with BF-200 ALA for the treatment of actinic keratosis: results of a multicentre, randomized, observerblind phase III study in comparison with a registered methyl-5-aminolaevulinate cream and placebo. Br J Dermatol. 2012 Jan;166(1):137-46.

10 Moseley $\mathrm{H}$. Total effective fluence: a useful concept in photodynamic therapy. Lasers Med Sci. 1996;11(2):139-43.

11 Karrer S, Kohl E, Feise K, Hiepe-Wegener D, Lischner S, Philipp-Dormston W, et al. Photodynamic therapy for skin rejuvenation: review and summary of the literature-results of a consensus conference of an expert group for aesthetic photodynamic therapy. J Dtsch Dermatol Ges. 2013 Feb;11(2):137-48.

12 Touma D, Yaar M, Whitehead S, Konnikov N, Gilchrest BA. A trial of short incubation, broad-area photodynamic therapy for facial actinic keratoses and diffuse photodamage. Arch Dermatol. 2004 Jan;140(1):33-40.

13 Goldman MP, Atkin D, Kincad S. PDT/ ALA in the treatment of actinic damage: real world experience. J Lasers Med Surg. 2002;14:S24.

14 Ruiz-Rodriguez R, Sanz-Sánchez T, Córdoba S. Photodynamic photorejuvenation. Dermatol Surg. 2002 Aug;28(8):742-4.

15 Avram DK, Goldman MP. Effectiveness and safety of ALA-IPL in treating actinic keratoses and photodamage. J Drugs Dermatol. 2004 Jan-Feb;3(1 Suppl):S36-9.

16 Alster TS, Tanzi EL, Welsh EC. Photorejuvenation of facial skin with topical $20 \% 5$-aminolevulinic acid and intense pulsed light treatment: a split-face comparison study. J Drugs Dermatol. 2005 Jan-Feb;4(1):35-8.

17 Bjerring P, Christiansen K, Troilius A, Bekhor $\mathrm{P}$, de Leeuw J. Skin fluorescence controlled photodynamic photorejuvenation (wrinkle reduction) [wrinkle reduction]. Lasers Surg Med. 2009 Jul;41(5):327-36.

18 Kosaka S, Yasumoto M, Akilov OE, Hasan T, Kawana S. Comparative split-face study of 5 -aminolevulinic acid photodynamic therapy with intense pulsed light for photorejuvenation of Asian skin. J Dermatol. 2010 Dec; 37(12):1005-10.

19 Haddad A, Santos ID, Gragnani A, Ferreira LM. The effect of increasing fluence on the treatment of actinic keratosis and photodamage by photodynamic therapy with 5 -aminolevulinic acid and intense pulsed light. Photomed Laser Surg. 2011 Jun;29(6):42732. 
20 Piccioni A, Fargnoli MC, Schoinas S, Suppa M, Frascione P, Ginebri A, et al. Efficacy and tolerability of 5-aminolevulinic acid $0.5 \%$ liposomal spray and intense pulsed light in wrinkle reduction of photodamaged skin. J Dermatolog Treat. 2011 Oct;22(5):247-53.

21 Babilas P, Knobler R, Hummel S, Gottschaller C, Maisch T, Koller M, et al. Variable pulsed light is less painful than light-emitting diodes for topical photodynamic therapy of actinic keratosis: a prospective randomized controlled trial. Br J Dermatol. 2007 Jul;157(1): 111-7.

22 Xi Z, Shuxian Y, Zhong L, Hui Q, Yan W, Huilin D, et al. Topical 5-aminolevulinic acid with intense pulsed light versus intense pulsed light for photodamage in Chinese patients. Dermatol Surg. 2011 Jan;37(1):31-40.

23 Dover JS, Bhatia AC, Stewart B, Arndt KA. Topical 5-aminolevulinic acid combined with intense pulsed light in the treatment of photoaging. Arch Dermatol. 2005 Oct;141(10): 1247-52.

24 Gold MH, Bradshaw VL, Boring MM, Bridges TM, Biron JA. Split-face comparison of photodynamic therapy with 5-aminolevulinic acid and intense pulsed light versus intense pulsed light alone for photodamage. Dermatol Surg. 2006 Jun;32(6):795-801.

25 Gold MH, Biron JA. Safety and Cosmetic Effects of Photodynamic Therapy using Hexyl Aminolevulinate and Intense Pulsed Light: A Pilot Study Conducted in Subjects with Mildto-moderate Facial Photodamage. J Clin Aesthet Dermatol. 2013 Oct;6(10):27-31.

26 Torezan L, Chaves Y, Niwa A, Sanches JA Jr, Festa-Neto C, Szeimies RM. A pilot split-face study comparing conventional methyl aminolevulinate-photodynamic therapy (PDT) with microneedling-assisted PDT on actinically damaged skin. Dermatol Surg. 2013 Aug; 39(8):1197-201.

27 Ruiz-Rodriguez R, López L, Candelas D, Zelickson B. Enhanced efficacy of photodynamic therapy after fractional resurfacing: fractional photodynamic rejuvenation. J Drugs Dermatol. 2007 Aug;6(8):818-20.

28 Sanclemente G, Medina L, Villa JF, Barrera LM, Garcia HI. A prospective split-face double-blind randomized placebo-controlled trial to assess the efficacy of methyl aminolevulinate + red-light in patients with facial photodamage. J Eur Acad Dermatol Venereol. 2011 Jan;25(1):49-58.

29 Sanclemente G, Correa LA, Garcia JJ, Barrera M, Villa JF, Garcia HI. Methyl aminolevulinate plus red light vs. placebo plus red light in the treatment of photodamaged facial skin: histopathological findings. Clin Exp Dermatol. 2012 Jun;37(4):379-86.

30 Park MY, Sohn S, Lee ES, Kim YC. Photorejuvenation induced by 5 -aminolevulinic acid photodynamic therapy in patients with actinic keratosis: a histologic analysis. J Am Acad Dermatol. 2010 Jan;62(1):85-95.

31 Park JY, Jang YH, Kim YS, Sohn S, Kim YC. Ultrastructural changes in photorejuvenation induced by photodynamic therapy in a photoaged mouse model. Eur J Dermatol. 2013 JulAug;23(4):471-7.

32 Orringer JS, Voorhees JJ, Hamilton T, Hammerberg C, Kang S, Johnson TM, et al. Dermal matrix remodeling after nonablative laser therapy. J Am Acad Dermatol. 2005 Nov; 53(5):775-82.

33 Zane C, Capezzera R, Sala R, Venturini M, Calzavara-Pinton P. Clinical and echographic analysis of photodynamic therapy using methylaminolevulinate as sensitizer in the treatment of photodamaged facial skin. Lasers Surg Med. 2007 Mar;39(3):203-9.

34 Lynn DD, Umari T, Dunnick CA, Dellavalle RP. The epidemiology of acne vulgaris in late adolescence. Adolesc Health Med Ther. 2016 Jan;7:13-25.

35 Collier CN, Harper JC, Cafardi JA, Cantrell WC, Wang W, Foster KW, et al. The prevalence of acne in adults 20 years and older. J Am Acad Dermatol. 2008 Jan;58(1):56-9.

36 Eichenfield LF, Del Rosso JQ, Mancini AJ, Cook-Bolden F, Stein Gold L, Desai S, et al. Evolving perspectives on the etiology and pathogenesis of acne vulgaris. J Drugs Dermatol. 2015 Mar;14(3):263-72.

37 Sakamoto FH, Lopes JD, Anderson RR. Photodynamic therapy for acne vulgaris: a critical review from basics to clinical practice: part I. Acne vulgaris: when and why consider photodynamic therapy? J Am Acad Dermatol. 2010 Aug;63(2):183-93

38 Hongcharu W, Taylor CR, Chang Y, Aghassi D, Suthamjariya K, Anderson RR. Topical ALA-photodynamic therapy for the treatment of acne vulgaris. J Invest Dermatol. 2000 Aug;115(2):183-92.

39 Akaraphanth R, Kanjanawanitchkul W, Gritiyarangsan P. Efficacy of ALA-PDT vs blue light in the treatment of acne. Photodermatol Photoimmunol Photomed. 2007 Oct; 23(5):186-90.

40 Serini SM, Cannizzaro MV, Dattola A, Garofalo V, Del Duca E, Ventura A, et al. The efficacy and tolerability of 5-aminolevulinic acid $5 \%$ thermosetting gel photodynamic therapy (PDT) in the treatment of mild-to-moderate acne vulgaris. A two-center, prospective assessor-blinded, proof-of-concept study. J Cosmet Dermatol. 2019 Feb;18(1):156-62.

41 Pollock B, Turner D, Stringer MR, Bojar RA, Goulden V, Stables GI, et al. Topical aminolaevulinic acid-photodynamic therapy for the treatment of acne vulgaris: a study of clinical efficacy and mechanism of action. Br J Dermatol. 2004 Sep;151(3):616-22.

42 Hong SB, Lee MH. Topical aminolevulinic acid-photodynamic therapy for the treatment of acne vulgaris. Photodermatol Photoimmunol Photomed. 2005 Dec;21(6):322-5.

43 Pariser DM, Eichenfield LF, Bukhalo M, Waterman G, Jarratt M; PDT Study Group. Photodynamic therapy with methyl aminolaevulinate $80 \mathrm{mg} \mathrm{g}(-1)$ for severe facial acne vulgaris: a randomized vehicle-controlled study. Br J Dermatol. 2016 Apr;174(4):770-7.
44 Nicklas C, Rubio R, Cárdenas C, Hasson A. Comparison of efficacy of aminolaevulinic acid photodynamic therapy vs. adapalene gel plus oral doxycycline for treatment of moderate acne vulgaris-A simple, blind, randomized, and controlled trial. Photodermatol Photoimmunol Photomed. 2019 Jan;35(1): 3-10.

45 Yang GL, Zhao M, Wang JM, He CF, Luo Y, Liu HY, et al. Short-term clinical effects of photodynamic therapy with topical 5 -aminolevulinic acid for facial acne conglobata: an open, prospective, parallel-arm trial. Photodermatol Photoimmunol Photomed. 2013 Oct;29(5):233-8

46 Zhang L, Wu Y, Zhang Y, Liu X, Wang B, Wang $\mathrm{P}$, et al. Topical 5-aminolevulinic photodynamic therapy with red light vs intense pulsed light for the treatment of acne vulgaris: A spilit face, randomized, prospective study. Dermatoendocrinol. 2017 Oct;9(1):e1375634.

47 Rojanamatin J, Choawawanich P. Treatment of inflammatory facial acne vulgaris with intense pulsed light and short contact of topical 5-aminolevulinic acid: a pilot study. Dermatol Surg. 2006 Aug;32(8):991-6.

48 Santos MA, Belo VG, Santos G. Effectiveness of photodynamic therapy with topical 5-aminolevulinic acid and intense pulsed light versus intense pulsed light alone in the treatment of acne vulgaris: comparative study. Dermatol Surg. 2005 Aug;31(8 Pt 1):910-5.

49 Wiegell SR, Wulf HC. Photodynamic therapy of acne vulgaris using methyl aminolaevulinate: a blinded, randomized, controlled trial. Br J Dermatol. 2006 May;154(5):969-76.

50 Kim TI, Ahn HJ, Kang IH, Jeong KH, Kim NI, Shin MK. Nonablative fractional laser-assisted daylight photodynamic therapy with topical methyl aminolevulinate for moderate to severe facial acne vulgaris: results of a randomized and comparative study. Photodermatol Photoimmunol Photomed. 2017 Sep;33(5):253-9.

51 Goldman MP, Boyce SM. A single-center study of aminolevulinic acid and $417 \mathrm{NM}$ photodynamic therapy in the treatment of moderate to severe acne vulgaris. J Drugs Dermatol. 2003 Aug;2(4):393-6.

52 Alexiades-Armenakas M. Long-pulsed dye laser-mediated photodynamic therapy combined with topical therapy for mild to severe comedonal, inflammatory, or cystic acne. J Drugs Dermatol. 2006 Jan;5(1):45-55.

53 Seo HM, Min HG, Kim HJ, Shin JH, Nam SH, Han KS, et al. Effects of repetitive photodynamic therapy using indocyanine green for acne vulgaris. Int J Dermatol. 2016 Oct; 55(10):1157-63.

54 Bryld LE, Jemec GB. Photodynamic therapy in a series of rosacea patients. J Eur Acad Dermatol Venereol. 2007 Oct;21(9):1199-202.

55 Suárez Valladares MJ, Eiris Salvado N, Rodríguez Prieto MA. Treatment of hidradenitis suppurativa with intralesional photodynamic therapy with 5-aminolevulinic acid and 630nm laser beam. J Dermatol Sci. 2017 Mar; 85(3):241-6. 
56 Fadel MA, Tawfik AA. New topical photodynamic therapy for treatment of hidradenitis suppurativa using methylene blue niosomal gel: a single-blind, randomized, comparative study. Clin Exp Dermatol. 2015 Mar;40(2): 116-22.

57 In SI, Lee JY, Kim YC. Topical photodynamic therapy for nevus sebaceous on the face. Eur $J$ Dermatol. 2010 Sep-Oct;20(5):590-2.

58 Miguel-Gomez L, Vano-Galvan S, Perez-Garcia B, Carrillo-Gijon R, Jaen-Olasolo P. Treatment of folliculitis decalvans with photodynamic therapy: results in 10 patients. J Am Acad Dermatol. 2015 Jun;72(6):1085-7.

59 Smits T, Kleinpenning MM, van Erp PE, van de Kerkhof PC, Gerritsen MJ. A placebo-controlled randomized study on the clinical effectiveness, immunohistochemical changes and protoporphyrin IX accumulation in fractionated 5-aminolaevulinic acid-photodynamic therapy in patients with psoriasis. $\mathrm{Br} J$ Dermatol. 2006 Aug;155(2):429-36.

60 Fransson J, Ros AM. Clinical and immunohistochemical evaluation of psoriatic plaques treated with topical 5-aminolaevulinic acid photodynamic therapy. Photodermatol Photoimmunol Photomed. 2005 Dec;21(6):32632.

61 Radakovic-Fijan S, Blecha-Thalhammer U, Schleyer V, Szeimies RM, Zwingers T, Hönigsmann H, et al. Topical aminolaevulinic acid-based photodynamic therapy as a treatment option for psoriasis? Results of a randomized, observer-blinded study. $\mathrm{Br} \mathrm{J}$ Dermatol. 2005 Feb;152(2):279-83.

62 Schleyer V, Radakovic-Fijan S, Karrer S, Zwingers $\mathrm{T}$, Tanew A, Landthaler $\mathrm{M}$, et al. Disappointing results and low tolerability of photodynamic therapy with topical 5-aminolaevulinic acid in psoriasis. A randomized, double-blind phase I/II study. J Eur Acad Dermatol Venereol. 2006 Aug;20(7):823-8.

63 Collins P, Robinson DJ, Stringer MR, Stables GI, Sheehan-Dare RA. The variable response of plaque psoriasis after a single treatment with topical 5-aminolaevulinic acid photodynamic therapy. Br J Dermatol. 1997 Nov; 137(5):743-9.

64 Robinson DJ, Collins P, Stringer MR, Vernon DI, Stables GI, Brown SB, et al. Improved response of plaque psoriasis after multiple treatments with topical 5-aminolaevulinic acid photodynamic therapy. Acta Derm Venereol. 1999 Nov;79(6):451-5.

65 Mostafa D, Moussa E, Alnouaem M. Evaluation of photodynamic therapy in treatment of oral erosive lichen planus in comparison with topically applied corticosteroids. Photodiagn Photodyn Ther. 2017 Sep;19:56-66.

66 Bakhtiari S, Azari-Marhabi S, Mojahedi SM, Namdari M, Rankohi ZE, Jafari S. Comparing clinical effects of photodynamic therapy as a novel method with topical corticosteroid for treatment of Oral Lichen Planus. Photodiagn Photodyn Ther. 2017 Dec;20:159-64.

67 Jajarm HH, Falaki F, Sanatkhani M, Ahmadzadeh M, Ahrari F, Shafaee H. A com- parative study of toluidine blue-mediated photodynamic therapy versus topical corticosteroids in the treatment of erosive-atrophic oral lichen planus: a randomized clinical controlled trial. Lasers Med Sci. 2015 Jul;30(5): 1475-80.

68 Mirza S, Rehman N, Alrahlah A, Alamri WR, Vohra F. Efficacy of photodynamic therapy or low level laser therapy against steroid therapy in the treatment of erosive-atrophic oral lichen planus. Photodiagn Photodyn Ther. 2018 Mar;21:404-8.

69 Helgesen AL, Warloe T, Pripp AH, Kirschner $\mathrm{R}$, Peng Q, Tanbo T, et al. Vulvovaginal photodynamic therapy vs. topical corticosteroids in genital erosive lichen planus: a randomized controlled trial. Br J Dermatol. 2015 Nov; 173(5):1156-62.

70 Hillemanns P, Untch M, Pröve F, Baumgartner R, Hillemanns M, Korell M. Photodynamic therapy of vulvar lichen sclerosus with 5-aminolevulinic acid. Obstet Gynecol. 1999 Jan;93(1):71-4.

71 Lan T, Zou Y, Hamblin MR, Yin R. 5-Aminolevulinic acid photodynamic therapy in refractory vulvar lichen sclerosus et atrophicus: series of ten cases. Photodiagn Photodyn Ther. 2018 Mar;21:234-8.

72 Sotiriou E, Panagiotidou D, Ioannidis D. An open trial of 5-aminolevulinic acid photodynamic therapy for vulvar lichen sclerosus. Eur J Obstet Gynecol Reprod Biol. 2008 Dec; 141(2):187-8

73 Maździarz A, Osuch B, Kowalska M, Nalewczyńska A, Śpiewankiewicz B. Photodynamic therapy in the treatment of vulvar lichen sclerosus. Photodiagn Photodyn Ther. 2017 Sep; 19:135-9.

74 Biniszkiewicz T, Olejek A, Kozak-Darmas I, Sieroń A. Therapeutic effects of 5-ALA-induced photodynamic therapy in vulvar lichen sclerosus. Photodiagn Photodyn Ther. 2005 Jun;2(2):157-60.

75 Zawislak AA, McCluggage WG, Donnelly RF, Maxwell P, Price JH, Dobbs SP, et al. Response of vulval lichen sclerosus and squamous hyperplasia to photodynamic treatment using sustained topical delivery of aminolevulinic acid from a novel bioadhesive patch system. Photodermatol Photoimmunol Photomed. 2009 Apr;25(2):111-3.

76 Shi L, Miao F, Zhang LL, Zhang GL, Wang PR, Ji J, et al. Comparison of 5-aminolevulinic acid photodynamic therapy and clobetasol propionate in treatment of vulvar lichen sclerosus. Acta Derm Venereol. 2016 Jun;96(5): 684-8.

77 Olejek A, Steplewska K, Gabriel A, KozakDarmas I, Jarek A, Kellas-Sleczka S, et al. Efficacy of photodynamic therapy in vulvar lichen sclerosus treatment based on immunohistochemical analysis of CD34, CD44, myelin basic protein, and Ki67 antibodies. Int J Gynecol Cancer. 2010 Jul;20(5):879-87.

78 Osiecka BJ, Jurczyszyn K, Nockowski P, Murawski M, Ziółkowski P. Photodynamic therapy with green light for the treatment of vul- var lichen sclerosus - preliminary results. Photodiagn Photodyn Ther. 2017 Mar; 17: 185-7.

79 Karrer S, Abels C, Landthaler M, Szeimies RM. Topical photodynamic therapy for localized scleroderma. Acta Derm Venereol. 2000 Jan-Feb;80(1):26-7.

80 Batchelor R, Lamb S, Goulden V, Stables G, Goodfield M, Merchant W. Photodynamic therapy for the treatment of morphoea. Clin Exp Dermatol. 2008 Aug;33(5):661-3.

81 Ud-Din S, Thomas G, Morris J, Bayat A. Photodynamic therapy: an innovative approach to the treatment of keloid disease evaluated using subjective and objective non-invasive tools. Arch Dermatol Res. 2013 Apr;305(3): 205-14.

82 Fernández-Guarino M, Pérez-García B, Harto A, Jaén P. Discoid lupus erythematosus: good response to treatment with photodynamic therapy. J Eur Acad Dermatol Venereol. 2008 Sep;22(9):1142-3.

83 Debu A, Girard C, Bessis D. Discoid lupus erythematosus successfully treated by photodynamic therapy. Br J Dermatol. 2015 Mar; 172(3):821-2.

84 Fai D, Romano I, Cassano N, Vena GA. Cutaneous lupus erythematosus of the scalp treated with methyl-aminolevulinate photodynamic therapy: a case report. G Ital Dermatol Venereol. 2012 Apr;147(2):213-5.

85 Romero-Maté A, Castaño-Suárez E, GarcíaDonoso C, Martínez-Morán C, Meseguer-Yebra C, Borbujo J. Unsuccessful treatment of recalcitrant cutaneous discoid lupus erythematosus with photodynamic therapy. Photodermatol Photoimmunol Photomed. 2010 Jun;26(3):156-8.

86 Berking C, Hegyi J, Arenberger P, Ruzicka T, Jemec GB. Photodynamic therapy of necrobiosis lipoidica-a multicenter study of $18 \mathrm{pa}$ tients. Dermatology. 2009;218(2):136-9.

87 Kaae J, Philipsen PA, Wulf HC. Photodynamic therapy of necrobiosis lipoidica using methyl aminolevulinate: A retrospective follow-up study. Photodiagn Photodyn Ther. 2018 Jun;22:223-6.

88 Ross EV, Romero R, Kollias N, Crum C, Anderson RR. Selectivity of protoporphyrin IX fluorescence for condylomata after topical application of 5-aminolaevulinic acid: implications for photodynamic treatment. Br J Dermatol. 1997 Nov;137(5):736-42.

89 Stender IM, Wulf HC. Photodynamic therapy of recalcitrant warts with 5 -aminolevulinic acid: a retrospective analysis. Acta Derm Venereol. 1999 Sep;79(5):400-1.

90 Stender IM, Lock-Andersen J, Wulf HC. Recalcitrant hand and foot warts successfully treated with photodynamic therapy with topical 5-aminolaevulinic acid: a pilot study. Clin Exp Dermatol. 1999 May;24(3):154-9.

91 Ohtsuki A, Hasegawa T, Hirasawa Y, Tsuchihashi H, Ikeda S. Photodynamic therapy using light-emitting diodes for the treatment of viral warts. J Dermatol. 2009 Oct;36(10):5258. 
92 Wang YS, Tay YK, Kwok C, Tan E. Photodynamic therapy with $20 \%$ aminolevulinic acid for the treatment of recalcitrant viral warts in an Asian population. Int J Dermatol. 2007 Nov; 46(11):1180-4.

93 Schroeter CA, Pleunis J, van Nispen tot Pannerden C, Reineke T, Neumann HA. Photodynamic therapy: new treatment for therapy-resistant plantar warts. Dermatol Surg. 2005 Jan;31(1):71-5.

94 Stender IM, Na R, Fogh H, Gluud C, Wulf HC. Photodynamic therapy with 5-aminolaevulinic acid or placebo for recalcitrant foot and hand warts: randomised doubleblind trial. Lancet. 2000 Mar;355(9208): 963-6.

95 Schroeter CA, Kaas L, Waterval JJ, Bos PM, Neumann HA. Successful treatment of periungual warts using photodynamic therapy: a pilot study. J Eur Acad Dermatol Venereol. 2007 Oct;21(9):1170-4.

96 Huang K, Xie Y, Li M, Liu D, Su J, Li F, et al. A comparative study: superficial shaving combined with photodynamic therapy versus cryotherapy in the treatment of recalcitrant plantar warts. Lasers Surg Med. 2020. DOI: $10.1002 / \mathrm{lsm} .23212$

97 Wu L, Chen W, Su J, Li F, Chen M, Zhu W, et al. Efficacy of the combination of superficial shaving with photodynamic therapy for recalcitrant periungual warts. Photodiagn Photodyn Ther. 2019 Sep;27: $340-4$.

98 Fathy G, Asaad MK, Rasheed HM. Daylight photodynamic therapy with methylene blue in plane warts: a randomized double-blind placebo-controlled study. Photodermatol Photoimmunol Photomed. 2017 Jul;33(4): 185-92.

99 Smucler R, Jatsová E. Comparative study of aminolevulic acid photodynamic therapy plus pulsed dye laser versus pulsed dye laser alone in treatment of viral warts. Photomed Laser Surg. 2005 Apr;23(2):202-5.

100 Fehr MK, Hornung R, Degen A, Schwarz VA, Fink D, Haller U, et al. Photodynamic therapy of vulvar and vaginal condyloma and intraepithelial neoplasia using topically applied 5-aminolevulinic acid. Lasers Surg Med. 2002;30(4):273-9.

101 Fehr MK, Hornung R, Schwarz VA, Simeon R, Haller U, Wyss P. Photodynamic therapy of vulvar intraepithelial neoplasia III using topically applied 5 -aminolevulinic acid. Gynecol Oncol. 2001 Jan;80(1):626.

102 Stefanaki IM, Georgiou S, Themelis GC, Vazgiouraki EM, Tosca AD. In vivo fluorescence kinetics and photodynamic therapy in condylomata acuminata. Br J Dermatol. 2003 Nov; 149(5):972-6.

103 Chen K, Chang BZ, Ju M, Zhang XH, Gu H. Comparative study of photodynamic therapy vs $\mathrm{CO} 2$ laser vaporization in treatment of condylomata acuminata: a randomized clinical trial. Br J Dermatol. 2007 Mar;156(3): 516-20.
104 Liang J, Lu XN, Tang H, Zhang Z, Fan J, Xu $\mathrm{JH}$. Evaluation of photodynamic therapy using topical aminolevulinic acid hydrochloride in the treatment of condylomata acuminata: a comparative, randomized clinical trial. Photodermatol Photoimmunol Photomed. 2009 Dec;25(6):293-7.

105 Wang XL, Wang HW, Wang HS, Xu SZ, Liao KH, Hillemanns P. Topical 5-aminolaevulinic acid-photodynamic therapy for the treatment of urethral condylomata acuminata. Br J Dermatol. 2004 Oct;151(4): $880-5$.

106 Hu S, Yang Y, Jiang B, Su D, Zhang L, Huang $Z$, et al. Treatment of condyloma acuminatum using the combination of laser ablation and ALA-PDT. Photodiagn Photodyn Ther. 2019 Mar;25:193-6.

107 Szeimies RM, Schleyer V, Moll I, Stocker M, Landthaler M, Karrer S. Adjuvant photodynamic therapy does not prevent recurrence of condylomata acuminata after carbon dioxide laser ablation-A phase III, prospective, randomized, bicentric, double-blind study. Dermatol Surg. 2009 May;35(5):757-64.

108 Shao X, Wang F, Xu B. Two-step irradiance schedule versus single-dose cold compress for pain control during 5-aminolevulinic acid-based photodynamic therapy of condyloma acuminatum. Lasers Surg Med. 2017 Dec;49(10):908-12.

109 Asilian A, Davami M. Comparison between the efficacy of photodynamic therapy and topical paromomycin in the treatment of Old World cutaneous leishmaniasis: a placebo-controlled, randomized clinical trial. Clin Exp Dermatol. 2006 Sep; 31(5):634-7.

110 Gardlo K, Hanneken S, Ruzicka T, Neumann NJ. [Photodynamic therapy of cutaneous leishmaniasis. A promising new therapeutic modality]. Hautarzt. 2004 Apr; 55(4):381-3. German.

111 Enk CD, Fritsch C, Jonas F, Nasereddin A, Ingber A, Jaffe CL, et al. Treatment of cutaneous leishmaniasis with photodynamic therapy. Arch Dermatol. 2003 Apr;139(4): $432-4$.

112 Ghaffarifar F, Jorjani O, Mirshams M, Miranbaygi $\mathrm{MH}$, Hosseini ZK. Photodynamic therapy as a new treatment of cutaneous leishmaniasis. East Mediterr Health J. 2006 Nov;12(6):902-8.

113 Sohl S, Kauer F, Paasch U, Simon JC. Photodynamic treatment of cutaneous leishmaniasis. J Dtsch Dermatol Ges. 2007 Feb;5(2): 128-30.

114 van der Snoek EM, Robinson DJ, van Hellemond JJ, Neumann HA. A review of photodynamic therapy in cutaneous leishmaniasis. J Eur Acad Dermatol Venereol. 2008 Aug;22(8):918-22.

115 Pizinger K, Cetkovska P, Kacerovska D, Kumpova M. Successful treatment of cutaneous leishmaniasis by photodynamic therapy and cryotherapy. Eur J Dermatol. 2009 Mar-Apr;19(2):172-3.
116 Akilov OE, Kosaka S, O’Riordan K, Hasan T. Parasiticidal effect of delta-aminolevulinic acid-based photodynamic therapy for cutaneous leishmaniasis is indirect and mediated through the killing of the host cells. Exp Dermatol. 2007 Aug;16(8):651-60.

117 Reveiz L, Maia-Elkhoury AN, Nicholls RS, Romero GA, Yadon ZE. Interventions for American cutaneous and mucocutaneous leishmaniasis: a systematic review update. PLoS One. 2013 Apr;8(4):e61843.

118 Lei X, Liu B, Huang Z, Wu J. A clinical study of photodynamic therapy for chronic skin ulcers in lower limbs infected with Pseudomonas aeruginosa. Arch Dermatol Res. 2015 Jan;307(1):49-55.

119 Darras-Vercambre S, Carpentier O, Vincent P, Bonnevalle A, Thomas P. Photodynamic action of red light for treatment of erythrasma: preliminary results. Photodermatol Photoimmunol Photomed. 2006 Jun;22(3):153-6.

120 Calzavara-Pinton PG, Venturini M, Sala R. A comprehensive overview of photodynamic therapy in the treatment of superficial fungal infections of the skin. J Photochem Photobiol B. 2005 Jan;78(1):1-6.

121 Figueiredo Souza LW, Souza SV, Botelho AC. Randomized controlled trial comparing photodynamic therapy based on methylene blue dye and fluconazole for toenail onychomycosis. Dermatol Ther (Heidelb). 2014 Jan-Feb;27(1):43-7.

122 Alberdi E, Gómez C. Efficiency of methylene blue-mediated photodynamic therapy vs intense pulsed light in the treatment of onychomycosis in the toenails. Photodermatol Photoimmunol Photomed. 2019 Mar;35(2): 69-77.

123 Tardivo JP, Wainwright M, Baptista M Small scale trial of photodynamic treatment of onychomycosis in São Paulo. J Photochem Photobiol B. 2015 Sep; 150:66-8.

124 Souza LW, Souza SV, Botelho AC. Distal and lateral toenail onychomycosis caused by Trichophyton rubrum: treatment with photodynamic therapy based on methylene blue dye. An Bras Dermatol. 2014 Jan-Feb;89(1):184-6.

125 Morgado LF, Trávolo AR, Muehlmann LA, Narcizo PS, Nunes RB, Pereira PA, et al. Photodynamic therapy treatment of onychomycosis with aluminium-phthalocyanine chloride nanoemulsions: A proof of concept clinical trial. J Photochem Photobiol B. 2017 Aug; 173:266-70.

126 Sotiriou E, Koussidou-Eremonti T, Chaidemenos G, Apalla Z, Ioannides D. Photodynamic therapy for distal and lateral subungual toenail onychomycosis caused by Trichophyton rubrum: preliminary results of a single-centre open trial. Acta Derm Venereol. 2010 Mar;90(2):216-7.

127 Gilaberte Y, Robres MP, Frías MP, GarcíaDoval I, Rezusta A, Aspiroz C. Methyl aminolevulinate photodynamic therapy for onychomycosis: a multicentre, randomized, controlled clinical trial. J Eur Acad Dermatol Venereol. 2017 Feb;31(2):347-54. 
128 Lyon JP, Pedroso e Silva Azevedo CM, Moreira LM, de Lima CJ, de Resende MA. Photodynamic antifungal therapy against chromoblastomycosis. Mycopathologia. 2011 Oct;172(4):293-7.

129 Mima EG, Vergani CE, Machado AL, Massucato EM, Colombo AL, Bagnato VS, et al. Comparison of Photodynamic Therapy versus conventional antifungal therapy for the treatment of denture stomatitis: a randomized clinical trial. Clin Microbiol Infect. 2012 Oct;18(10):E380-8.
130 Scwingel AR, Barcessat AR, Núñez SC, Ribeiro MS. Antimicrobial photodynamic therapy in the treatment of oral candidiasis in HIV-infected patients. Photomed Laser Surg. 2012 Aug;30(8):429-32.

131 García-Malinis AJ, Milagro Beamonte A, Torres Sopena L, García-Callen O, Puertolas-Villacampa P, Gilaberte Y. Cutaneous sporotrichosis treated with methylene bluedaylight photodynamic therapy. J Eur Acad Dermatol Venereol. 2018 Mar;32(3):e90-1.
132 Javed F, Samaranayake LP, Romanos GE. Treatment of oral fungal infections using antimicrobial photodynamic therapy: a systematic review of currently available evidence. Photochem Photobiol Sci. 2014 May; 13(5):726-34.

133 Calzavara-Pinton PG, Venturini M, Capezzera R, Sala R, Zane C. Photodynamic therapy of interdigital mycoses of the feet with topical application of 5-aminolevulinic acid. Photodermatol Photoimmunol Photomed. 2004 Jun;20(3):144-7. 